\title{
Comparação entre três métodos analíticos para determinação de soro em leite cru refrigerado
}

\author{
[Comparison of three analytical methods to determine serum \\ in refrigerated raw milk] \\ C. M. Souza ${ }^{1}$, E. S. Nicolau ${ }^{2}$, M. E. Lage², A. J. Mesquita ${ }^{3}$, K.O. Coelho ${ }^{4 *}$ \\ ${ }^{1}$ Universidade Federal de Goiás - UFG - Jataí, GO \\ ${ }^{2}$ Universidade Federal de Goiás - UFG - Goiânia, GO \\ ${ }^{3}$ Fundação de Amparo à Pesquisa do Estado de Goiás - FAPEG - Goiânia, GO \\ ${ }^{4}$ Bolsista PROBIP - Universidade Estadual de Goiás - UEG - São Luís de Montes Belos, GO
}

\section{RESUMO}

O objetivo deste experimento foi comparar três métodos analíticos para determinação de soro em leite cru refrigerado: cromatografia líquida de alta eficiência, ninidrina ácida e colorimétrico adaptado. Foram coletadas 100 amostras de leite cru refrigerado de tanques de expansão. Estas, quando submetidas à análise pelo método da ninidrina ácida, apresentaram $10(14,7 \%)$ amostras negativas e $58(85,3 \%)$ positivas. O teor médio de ácido siálico encontrado na técnica da ninidrina foi de $5,58 \mu \mathrm{g} / \mathrm{mL}$, com valor mais frequente de $2,70 \mu \mathrm{g} / \mathrm{mL}$. Das 68 amostras negativas pela cromatografia líquida de alta eficiência, duas foram positivas $(2,94 \%)$ e $66(97,06 \%)$ negativas, quando analisadas pelo método colorimétrico. A frequência relativa de amostras positivas foi de $32 \%$, com a CLAE apresentando a maior média de soro $(14,37 \%)$, seguida do método colorimétrico $(5,28 \%)$ e o da ninidrina ácida $(3,12 \%)$. A técnica de cromatografia líquida de alta eficiência diferiu dos métodos de ninidrina ácida e colorimétrico, enquanto os métodos da ninidrina e colorimétrico não diferiram entre si, podendo ambos serem utilizados como metodologias de triagem. Entre as três técnicas, a cromatografia líquida de alta eficiência foi a metodologia mais sensível na detecção e quantificação do soro em leite cru refrigerado.

Palavras-chave: CLAE, método da ninidrina ácida, método colorimétrico, GMP/CMP, fraude

\begin{abstract}
The objective of this study was to compare three analytical methods to determine serum in refrigerated raw milk. High-performance liquid chromatography (HPLC), acidic and colorimetric ninhydrin methods were applied. A collection of 100 samples of raw milk from cooled expansion tanks took place. The results showed that 10 samples $(14.7 \%)$ were negative and 58 (85.3\%) were positive for the acidic ninhydrin method. The mean sialic acid content found in the ninhydrin technique was $5.58 \mu \mathrm{g} / \mathrm{mL}$, with a more frequent value of $2.70 \mu \mathrm{g} / \mathrm{mL}$. From all $68 \mathrm{HPLC}$ negative samples, two were positive $(2.94 \%)$ and $66(97.06 \%)$ negative to the colorimetric method. The relative frequency of positive samples was 32\%, HPLC had the highest mean serum levels $(14.37 \%)$, followed by the colorimetric method (5.28\%) and acid ninhydrin (3.12\%). The highperformance liquid chromatography method was different from the acid and colorimetric ninhydrin methods. The ninhydrin and colorimetric methods were not different from each other, both of which could be used as screening methodologies. Among the three techniques, HPLC was the most sensitive methodology for the detection and quantification of serum in refrigerated raw milk.
\end{abstract}

Keywords: HPLC, ninhydrin acid method, colorimetric method, GMP/CMP, fraud

\section{INTRODUÇÃO}

Ao se analisar a qualidade do leite, alguns fatores devem ser considerados. Entre eles, são as fraudes que normalmente visam a aumentar o tempo de vida de prateleira ou o rendimento do produto. Uma fraude tem merecido atenção especial por implicar a incorporação de proteínas do soro em leite cru, leite em pó, queijos, leite UHT "ultra high temperature" e leite pasteurizado (Closs e Souza, 2011; Mareze e Marioto, 2015).

Recebido em 10 de dezembro de 2016

Aceito em 3 de fevereiro de 2017

* Autor para correspondência (corresponding author)

E-mail: kocoelho@yahoo.com.br 
Embora o valor nutricional da proteína do soro seja alto, a adição de soro ao leite precisa ser especificada com clareza, pois, caso contrário, é considerada fraude. A adição fraudulenta dessa proteína é normalmente detectada e quantificada por meio da determinação do caseinomacropeptídeo (CMP) (Sharma et al., 2013). Esse polipeptídeo, um componente específico do soro obtido após a coagulação do leite pela renina, deve estar ausente no leite em condições normais (Prata e Prata, 2012). Caso ocorra a presença de mais de $1 \%$ de soro determinado pela técnica CLAE, de acordo com a legislação, a prova será considerada positiva (Brasil, 2006).

Durante a fabricação do queijo, ocorre a hidrólise da $\kappa$-caseína do leite, no sítio de clivagem entre os aminoácidos $\mathrm{Phe}_{105}-\mathrm{Met}_{106}$. Com a clivagem, há a liberação da para-к-caseína, que permanece na coalhada, e de um peptídeo terminal de 64 aminoácidos, denominado glicomacropeptídeo (GMP), também chamado de caseinomacropeptídeo (CMP) ou ainda de caseinoglicomacropeptídeo (CGMP), que é removido com o soro. O CMP carreia todos os açúcares da $\kappa$-caseína, sendo um desses o ácido siálico ou N-acetilneuramínico (NANA). Há possibilidade de obtenção de fragmentos com ausência glicídica, e, nesse caso, o peptídeo terminal é designado de CMP. A fração glicídica do CMP é referida também como GMP e a determinação desse ácido em soro doce reflete a concentração de CMP presente no leite (Veloso et al., 2002).

O elevado interesse no estudo da composição da fração glicídica reside na importância nutricional, funcional e na grande diversidade das proteínas presentes no leite, o que tem resultado em acentuado desenvolvimento de métodos analíticos, os quais incluem técnicas que permitem não só a quantificação mas também a separação e a identificação das proteínas do leite.

Atualmente, os métodos oficiais para detecção de soro no leite compreendem o método quantitativo que utiliza a cromatografia líquida de alta eficiência (CLAE) (Brasil, 2006). Essa técnica é internacionalmente aceita para identificar e quantificar tanto o CMP (Fukuda et $a l$. , 2004) quanto o método qualitativo, utilizando-se o reativo de Ehrlich para a determinação qualitativa do ácido siálico (Brasil, 2006). Entretanto, essas técnicas são caras, difíceis de serem executadas e requerem mão de obra especializada.

Outros métodos têm sido descritos para a detecção e quantificação do CMP, entre os quais, os cromatográficos (Andrade et al., 2014; Noni et al., 2005), em particular a cromatografia de exclusão molecular, a CLAE em fase reversa (reversed-phase high-performance liquid chromatographic) (Andrade et al., 2014) e a cromatografia de troca iônica (Dias et al., 2009). A eletroforese capilar de zona com uma coluna hidrofílica de sílica fundida foi também utilizada com sucesso (Bremer et al., 2008). Outros métodos usados são a espectroscopia por absorção (Miralles et al., 2003) e os imunológicos (Veloso et al., 2002).

Visando à determinação quantitativa de ácido siálico (NANA) no leite, Fukuda et al. (1996) validaram o método espectrofotométrico mediante o emprego da técnica da ninidrina ácida. Tal metodologia, de acordo com Fukuda et al. (1996; 2004), pode ser utilizada como substituta das demais na detecção da adição de soro em leite. Esses autores ressaltam que o teor de CMP ou de ácido siálico em leite e seus derivados tem atuado como um importante marcador das ações proteolíticas. Somente no ano de 2006, por meio da Instrução Normativa $n^{\circ}$ 68 , de 12 de dezembro, foi aprovada a utilização da ninidrina ácida para a determinação quantitativa de ácido siálico livre e ligado à glicoproteína do leite como técnica oficial do Ministério da Agricultura, Pecuária e Abastecimento (Mapa) (Brasil, 2006; Marques et al., 2011).

A fim de trabalharem na rotina com uma técnica mais rápida, simples, fácil e econômica, que não necessita de mão de obra especializada, Oliveira et al. (1998) propuseram uma adaptação ao método qualitativo para detecção de soro no leite adotado pelo Mapa (Brasil, 1991), que foi denominado de método colorimétrico adaptado. A adaptação consistiu em não utilizar o reativo de Ehrlich, cuja finalidade era liberar o ácido siálico ligado ao CMP, usado como marcador para o soro, por meio de uma hidrólise ácida e, em sequência, detectado como um cromóforo púrpura após a reação com p dimetilaminobenzaldeído. 
Considerando o exposto, propôs-se o presente trabalho com o objetivo de comparar três metodologias: CLAE, ninidrina ácida e método colorimétrico adaptado, na determinação de soro em leite.

\section{MATERIAL E MÉTODOS}

O presente trabalho foi desenvolvido em parceria com uma indústria de laticínios do estado de Goiás, submetida à inspeção sanitária permanente do Serviço de Inspeção Federal (SIF). Foram coletadas 100 amostras de leite cru refrigerado em tanques de expansão, a uma temperatura média de $5,5^{\circ} \mathrm{C}$, de 24 propriedades rurais, com tempo médio de estocagem de 48 horas.

Para a coleta, procedeu-se à homogeneização do leite por cinco minutos e à ambientação do copo coletor. Foram coletadas alíquotas de $100 \mathrm{~mL}$ de leite, as quais, em seguida, foram transferidas para frascos, que foram previamente lavados e sanitizados com álcool a 70\%. Após a coleta, as amostras foram devidamente identificadas e acondicionadas em caixas isotérmicas contendo gelo reciclado. Imediatamente depois, foram transportadas ao Centro de Pesquisa da Escola de Veterinária e Zootecnia da Universidade Federal de Goiás (CPA/EVZ/UFG) e armazenadas a $18^{\circ} \mathrm{C}$ até o momento das análises.

As análises pelos métodos da ninidrina ácida e colorimétrico adaptado foram realizadas em espectrofotômetro Perkin Elmer Lambda 25UV/VIS com faixa de espectro de 190 a $1.100 \mathrm{~nm}$, com kit software L610 - 0109, UV Winlab (STD), versão 5.15 Rev. C, com lâmpada de tungstênio e deutério.

Para a determinação e a quantificação do CMP, adotou-se a metodologia descrita em Brasil (1991). Para determinação percentual do teor de soro pela técnica da CLAE, fez-se uma curva padrão com leite genuíno de procedência conhecida (Fig. 1).

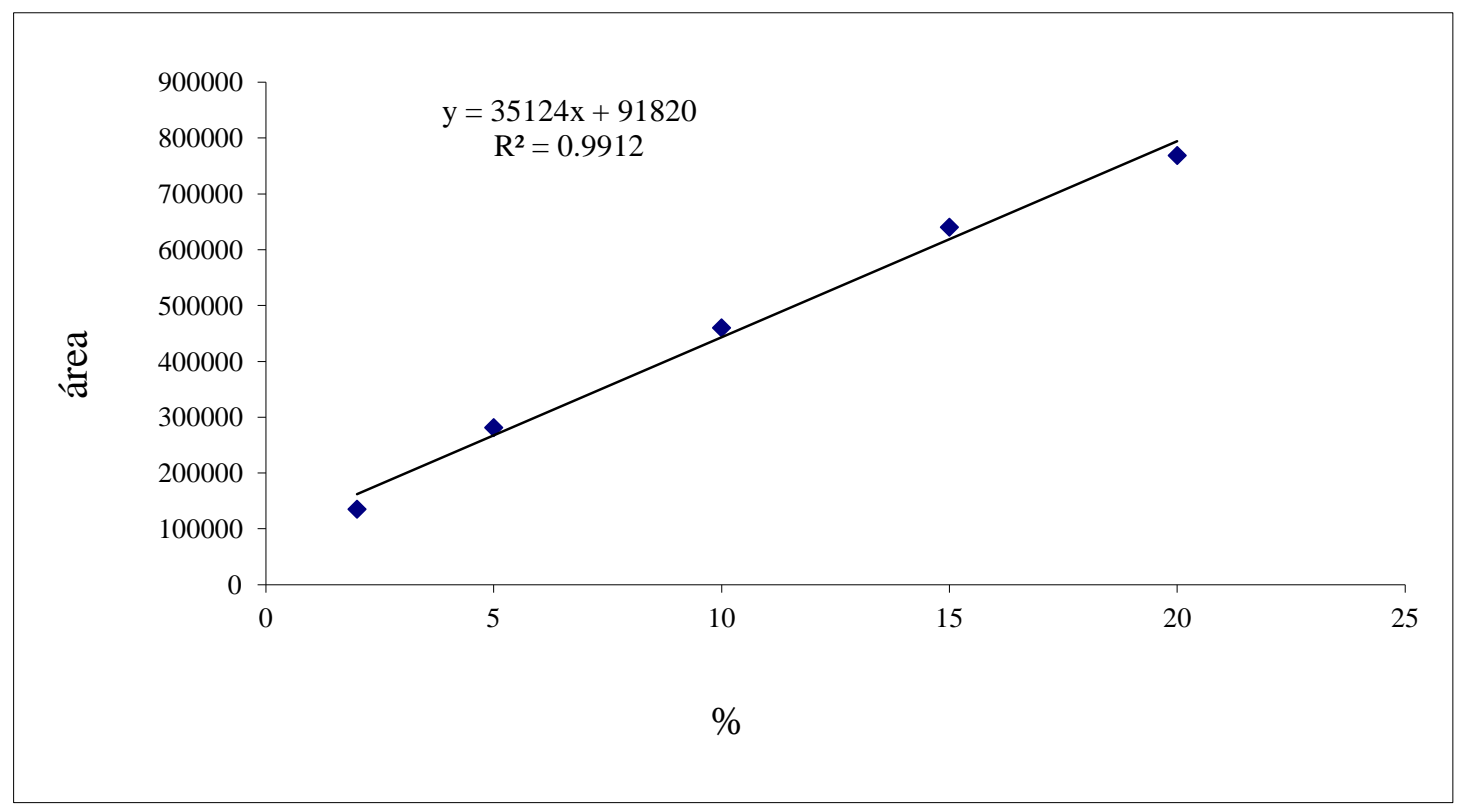

Figura 1. Curva padrão para determinação percentual do soro em leite cru refrigerado

Para obtenção da curva, o leite foi adulterado com soro de leite de composição padrão, nas proporções de 5\%, 10\%, 15\% e 20\% (Brasil, 1991). O soro de queijo utilizado na elaboração da curva padrão foi obtido após a adição do coalho em pó e subsequente coagulação da caseína em leite genuíno, coletado na fazenda da EV/UFG momentos antes das análises.
Para o preparo da amostra, $22 \mathrm{~mL}$ de leite foram tratados com $10 \mathrm{~mL}$ da solução de ácido tricloroacético (TCA) a 24\%, seguindo-se incubação a $25^{\circ} \mathrm{C} / 60 \mathrm{~min}$ em banho-maria, em repouso. Após esse período, realizaram-se duas filtrações: a primeira em filtro qualitativo (papel-filtro Whatman $\mathrm{n}^{\circ} 40$ ), descartando-se aproximadamente $5 \mathrm{~mL}$ do filtrado, e a segunda 
em filtro MILLIPORE de $0,45 \mu \mathrm{m}$ (MILLEX LCR com membrana PTFE modificada para filtração de solventes orgânicos e aquosos $0,45 \mu \mathrm{m}, 13 \mathrm{~mm}$, não esterilizada).

A determinação cromatográfica foi realizada com a injeção de $20 \mu \mathrm{L}$ do filtrado no cromatógrafo (GILSON 118 UV/VIS), que operou em vazão de $1 \mathrm{~mL} / \mathrm{min}$, e a detecção foi feita na faixa do UV-VIS, em comprimento de onda de 205nm, com a linha de base já devidamente estabilizada. A corrida cromatográfica foi realizada em aparelho de cromatografia líquida de alta eficiência (GILSON), com uma bomba isocrática (GILSON 306), com injetor automático ASTED - XL da marca GILSON, looping de $200 \mu \mathrm{L}$ e coluna Zorbax GF-250 Biosséries da Agilent de $9 \mathrm{~mm}$ de diâmetro interno por $250 \mathrm{~mm}$ de comprimento.

A fase estacionária da coluna foi composta por partículas esféricas de sílica, modificadas na superfície por zircônio estabilizado, e a fase ligada composta por monocamada molecular hidrofílica, com diâmetro de poro de $150 \mathrm{~A}^{\circ}$. A solução da fase móvel usada na separação constituiu um padrão fosfato com pH6 dissolvido em $1000 \mathrm{~mL}$ de água destilada (deionizada).

Foi construído um gráfico de porcentagem de soro "versus" a intensidade do sinal do detector, ou altura do pico, calculando-se a equação da reta de regressão, tendo sido aceitos valores de $\mathrm{r} \geq 0.95$. O cromatograma da amostra foi comparado com o do leite adicionado de soro e, em seguida, identificou-se o pico com o mesmo tempo de retenção do soro, calculando-se o percentual de soro na amostra por interpolação da leitura do sinal na reta de regressão do leite adicionado de soro. A prova foi considerada positiva quando a presença de soro foi superior a 1\% (Brasil, 1991).

Adotou-se a metodologia descrita por Oliveira et al. (1998), que se baseia na leitura da opacidade causada pelo resíduo de ácido siálico em espectrofotômetro na região visível do espectro, a $520 \mathrm{~nm}$.

Para determinação percentual do teor de soro pela técnica colorimétrica, fez-se uma curva padrão com leite genuíno de procedência conhecida. Para o seu preparo, o leite foi adulterado com soro de queijo de composição padrão nas proporções de $1 \%, 2 \%, 5 \%, 10 \% \mathrm{e}$ 20\% (Brasil, 1991; Brasil, 2006). O soro de queijo utilizado na elaboração da curva padrão foi obtido após a adição do coalho em pó e subsequente coagulação da caseína em leite genuíno, coletado na fazenda da EVZ/UFG momentos antes das análises.

Paralelamente, foi preparada uma amostra "branco", utilizando-se leites crus genuínos coletados na fazenda da EVZ/UFG durante a ordenha matutina, sendo seguidos todos os passos já descritos para extração da amostra.

Foram transferidos, para um béquer de $250 \mathrm{~mL}$, $10 \mathrm{~mL}$ da amostra de leite e adicionados, sob cuidadosa agitação, $10 \mathrm{~mL}$ de solução do ácido tricloroacético (TCA) a 24\%. Deixou-se a solução em repouso por 30 minutos, seguindo-se a filtração em papel-filtro (Whatman $n^{\circ} 40$ ) e a transferência de $15 \mathrm{~mL}$ do filtrado para tubo cônico de $35 \mathrm{~mL}$, com adição de $0,5 \mathrm{~mL}$ de solução de ácido fosfotúngstico a 20\%. Após a adição do ácido deixou a solução em repouso por 10 minutos, realizando, em sequência, a agitação do tubo e a leitura da absorbância em espectrofotômetro, utilizando-se comprimento de onda de $520 \mathrm{~nm}$.

O resultado final foi obtido por comparação entre os valores encontrados nas amostras de leite coletadas nos tanques de expansão, e a curva padrão previamente estabelecida. A prova foi considerada positiva quando o soro foi detectado em percentual igual ou superior a $3 \%$.

Foi adotada a metodologia descrita por Fukuda et al. (1996). Para a construção da curva padrão, preparou-se uma solução estoque contendo $294 \mu \mathrm{g}$ de ácido siálico/mL. A partir dessa solução, por diluição, foi preparada uma solução de trabalho contendo $98 \mu \mathrm{g}$ de ácido siálico/mL, de onde foram retiradas 10 alíquotas, em duplicatas, sendo a inicial de $0,01 \mathrm{~mL}$ e a final de $1 \mathrm{~mL}$, representando concentrações que variaram de 9,8 a $98 \mu \mathrm{g}$ de ácido siálico. Os volumes das alíquotas foram completados para $1 \mathrm{~mL}$ com água destilada. Adicionou-se, em cada tubo, $1 \mathrm{~mL}$ de ácido acético glacial e $1 \mathrm{~mL}$ de solução de ninidrina ácida (2,2 - Dihydroxy 1,3 indanedione - $\mathrm{C}_{9} \mathrm{H}_{6} \mathrm{O}_{4}$ - SIGMA Grade). Os tubos foram colocados em banho-maria por 10min, sendo, em seguida, esfriados em temperatura ambiente em 
banho de gelo. Em seguida, foi realizada a leitura a 470nm, para construção da curva padrão.

A cada $15 \mathrm{~mL}$ de leite, foram acrescidos, sob agitação, $15 \mathrm{~mL}$ de ácido tricloroacético (TCA) a $24 \%$. Após homogeneização e repouso por 30min, a mistura foi filtrada em papel-filtro (Whatman $\mathrm{n}^{\circ}$ 40). Do filtrado, foram retiradas alíquotas de $10 \mathrm{~mL}$, em duplicata, e adicionou-se, a cada uma delas, $1 \mathrm{~mL}$ de ácido fosfotúngstico a $20 \%$. Seguiu-se centrifugação a $3.500 \mathrm{rpm} / 10 \mathrm{~min}$, desprezou-se cuidadosamente o sobrenadante e dispersou-se o sedimento com $4 \mathrm{~mL}$ de álcool etílico 95\%, com o auxílio de um bastão de vidro, que foi enxaguado com $2 \mathrm{~mL}$ do álcool. Procedeu-se a uma nova centrifugação por 10min/3.500rpm. Desprezou-se novamente o sobrenadante e adicionaram-se, ao resíduo, $2 \mathrm{~mL}$ de ácido acético glacial e $1 \mathrm{~mL}$ do reagente de ninidrina ácida. Posteriormente à homogeneização, a mistura foi aquecida em banho-maria fervente por 10min. Após o desenvolvimento de cor, que variava de amareloclara a marrom-amarelada, a solução foi resfriada em água gelada até atingir a temperatura ambiente. Em seguida, fez-se a leitura da absorbância a 470nm.

O espectrofotômetro foi calibrado com o "branco", e as leituras foram transformadas em concentração de ácido N-acetilneuramínico (NANA) ou ácido siálico $(\mu \mathrm{g} / \mathrm{mL})$, utilizando-se a curva padrão elaborada com ácido siálico puro. O resultado final foi obtido por comparação da leitura da absorbância da amostra com a curva padrão de ácido siálico e expresso em $\mu \mathrm{g} / \mathrm{mL}$.

Com os resultados obtidos, realizou-se a ANOVA com posterior comparação das médias pelo teste de Tukey, com 5\% de probabilidade.

\section{RESULTADOS E DISCUSSÃO}

Das 100 amostras de leite cru refrigerado, coletadas em tanques de expansão, em $68 \%$ não foi detectada a presença de soro pela técnica da CLAE. Estas, quando submetidas à análise pelo método da ninidrina ácida, apresentaram teor médio de ácido siálico de $5,58 \mu \mathrm{g} / \mathrm{mL} \pm 5,70 \mu \mathrm{g} / \mathrm{mL}$. A moda, ou seja, o valor de maior frequência na distribuição, situou-se em $2,70 \mu \mathrm{g} / \mathrm{mL}$ NANA, e os valores mínimo e máximo encontrados foram de $1,96 \mu \mathrm{g} / \mathrm{mL}$ e $48,63 \mu \mathrm{g} / \mathrm{mL}$, respectivamente.
$\mathrm{O}$ valor mais frequente quando se empregou a técnica da ninidrina ácida $(2,70 \mu \mathrm{g} / \mathrm{mL})$ está de acordo com o teor médio para leite autêntico detectado por Fukuda et al. (1996) e com o recomendado na Instrução Normativa (IN) 68, que oficializou a técnica de detecção do ácido siálico livre e ligado à glicoproteína do leite. Segundo a Normativa, amostras de leite cru autêntico apresentam teor médio de 2,71 $\mu \mathrm{g} / \mathrm{mL} \pm 0,83 \mu \mathrm{g} / \mathrm{mL}$ de ácido siálico (Brasil, 2006). Das 68 amostras negativas pela CLAE e analisadas pelo método da ninidrina, apenas $14,7 \%$ foram classificadas como leite autêntico, enquanto $85,3 \%$ como leite fraudado.

Dentre as amostras consideradas fraudadas pelo método da ninidrina ácida, verificou-se teor máximo de soro de $48,63 \mu \mathrm{g} / \mathrm{mL}$, resultado superior ao teor médio de ácido siálico em amostras de soro industrial, que é de $42,35 \mu \mathrm{g} / \mathrm{mL}$ (Fukuda et al.,1996; Brasil, 2006), podendo chegar a um valor máximo de $70,5 \mu \mathrm{g} / \mathrm{mL}$ (Fukuda et al., 1996).

De acordo com a interpretação prática do método da ninidrina ácida realizada por Fukuda et al. (1996) para análise de leite cru em plataforma, o valor médio detectado de $5,58 \mu \mathrm{g} / \mathrm{mL} \pm 5,70 \mu \mathrm{g} / \mathrm{mL}$ de NANA, no presente trabalho, está classificado na categoria de suspeito, uma vez que o resultado encontra-se dentro do intervalo de $5,14<\mathrm{C} \leq 10,64 \mu \mathrm{g}$ de NANA livre/mL. A autora ressalta ainda que a detecção da adição de soro no leite é considerada negativa quando os valores são $\leq 5,14 \mu \mathrm{g}$ de NANA livre/mL de leite e positiva quando $>10,64 \mu \mathrm{g}$ de NANA livre/mL de leite. O valor médio encontrado no presente experimento $(5,58 \mu \mathrm{g} / \mathrm{mL})$ assemelha-se ao encontrado por Fukuda et al. (1996) para leite cru refrigerado, de $6,93 \mu \mathrm{g} / \mathrm{mL}$ de NANA, estando, portanto, incluído na faixa de categoria considerada suspeita de fraude por adição de soro. Esse valor de $5,58 \mu \mathrm{g} / \mathrm{mL}$, com desvio padrão de $\pm 5,70 \mu \mathrm{g} / \mathrm{mL}$, implicaria a suposição de conduta duvidosa do produtor, uma vez que as amostras foram coletadas em tanques de expansão. No entanto, devem-se considerar outros fatores, a temperatura do leite armazenado em tanques de expansão, o tempo de armazenamento e a higienização dos tanques. Assim, o teor de NANA em leites com mais horas de estocagem sob refrigeração, bem como obtidos sob 
higienização precária, pode apresentar multiplicação de microrganismos psicrotróficos, o que acarreta certa hidrólise proteica com posterior liberação do CMP, que, segundo Fukuda et al. (1996), são os responsáveis pelo teor de ácido siálico nas amostras.

O leite enquadrado na categoria suspeita segundo Fukuda et al. (1996) deve receber um tratamento diferenciado, não podendo ser condenado e tampouco considerado negativo. O ideal seria, se possível, fazer rastreamento e acompanhamento sistemático de todo o ciclo de produção, do acondicionamento e do transporte desse leite.

No caso da adição fraudulenta do soro de queijo em leite, o fraudador pode proceder de duas formas. Uma delas é mediante a adição de quantidades ínfimas de soro, o que caracteriza uma fraude sutil, que pouco contribuirá para o aumento do teor de ácido siálico. Consequentemente, a fraude não será detectada devido aos valores situarem-se em níveis considerados normais. Por isso, sugerem-se considerar como padrão os valores médios estabelecidos pela legislação. A outra maneira de enganar o consumidor é por meio da adição grosseira do soro. Nesta, a intenção do fraudador é adicionar uma quantidade maior de soro, que tende ao exagero, visando-se lucros cada vez mais altos (Fukuda et al., 1996).

Ainda em relação às 68 amostras negativas pela CLAE, duas foram positivas $(2,94 \%)$, quando analisadas pelo método colorimétrico adaptado. Nesse caso, ressalta-se que 66 amostras $(97,06 \%)$ podem ser consideradas como leite genuíno. Tendo como base esse resultado, pode-se afirmar que o método colorimétrico foi o que mais se aproximou da técnica CLAE em termos de sensibilidade, quando comparado com o da ninidrina ácida $(14,70 \%)$.

No presente estudo, foram encontradas 32 amostras positivas para presença de soro pelo método da CLAE. A média de soro foi de $14,37 \%$, superior, portanto, às médias detectadas pelos métodos colorimétrico adaptado $(5,28 \%)$ e da ninidrina ácida $(3,12 \%)$.

A CLAE apresentou valores mínimo e máximo de $0,44 \%$ e $41,36 \%$, o método colorimétrico de $0,02 \%$ e $14,51 \%$, e a ninidrina ácida de $0,69 \%$ e $9,82 \%$. Ao se compararem os métodos, verificase que houve diferença significativa $(\mathrm{P}<0,01)$ entre eles, tendo o método da CLAE apresentado maior sensibilidade na detecção de soro de queijo que os métodos colorimétrico adaptado e da ninidrina ácida. Portanto, a CLAE possui melhor capacidade em distinguir duas concentrações próximas, ou seja, apresenta melhor "sensibilidade". A CLAE constitui uma metodologia validada e empregada como método oficial pelo Mapa (Brasil, 1991; Brasil, 2006) na detecção e quantificação do caseinomacropeptídeo no leite, além de internacionalmente reconhecida. Comparando a média do teor de soro obtida pelo método colorimétrico $(5,28 \%)$ com a do método da ninidrina ácida $(3,12 \mu \mathrm{g} / \mathrm{mL})$, observam-se que a sensibilidade foi a mesma.

Ao se compararem os resultados obtidos por meio das técnicas CLAE, colorimétrico adaptado e da ninidrina ácida, nas 100 amostras analisadas, observa-se diferença significativa $(\mathrm{P}<0,01)$ entre eles (Tukey 5\%). Nota-se que a média geral "quantitativo" de detecção de soro nas amostras avaliadas da CLAE $(4,59 \%)$ difere $(\mathrm{P}<0,05)$ da ninidrina ácida $(1,66 \%)$ e do colorimétrico $(1,89 \%)$. Por outro lado, as médias obtidas pelos métodos da ninidrina e colorimétrico não diferem entre si (Tab. 1).

Comparando-se os três métodos de detecção de soro em leite, tendo como base a média da concentração de soro nas 100 amostras analisadas, verifica-se que as metodologias diferiram entre si, CLAE $(4,59 \pm 9,58)$, colorimétrico $(1,86 \pm 3,27)$ e da ninidrina ácida $(1,66 \pm 2,20)$ e seus respectivos desvios. Não foi encontrada comparação dos três métodos na literatura consultada, porém Hernández et al. (2009) analisaram 60 amostras de leite cru pelo Stick cGMP e os resultados obtidos foram comparados pela CLAE e pelo método colorimétrico do ácido siálico. Os resultados obtidos pelos três métodos foram semelhantes, sendo soro de queijo encontrado em $75 \%$ das amostras.

Os valores mínimos e máximos obtidos por meio dos métodos CLAE, colorimétricos e da ninidrina foram de $0 \%$ e $41,36 \%, 0 \%$ e $14,51 \%$, $0,20 \%$ e $9,82 \%$, nessa ordem. As médias, juntamente com os valores mínimos e máximos para cada metodologia, estão apresentadas na Fig. 2. 
Tabela 1. Médias e desvio padrão dos resultados das análises de soro "quantitativo" em leite pelos métodos da ninidrina ácida, colorimétrico e CLAE

\begin{tabular}{ccc}
\hline \multicolumn{3}{c}{ Percentual médio de soro identificado pelos métodos } \\
\hline Ninidrina ácida & Colorimétrico & CLAE \\
$1,66 \pm 2,20 \mathrm{a}$ & $1,86 \pm 3,27 \mathrm{a}$ & $4,59 \pm 9,58 \mathrm{~b}$ \\
\hline
\end{tabular}

Médias seguidas de uma mesma letra não diferem entre si (Tukey, $5 \%$ ).

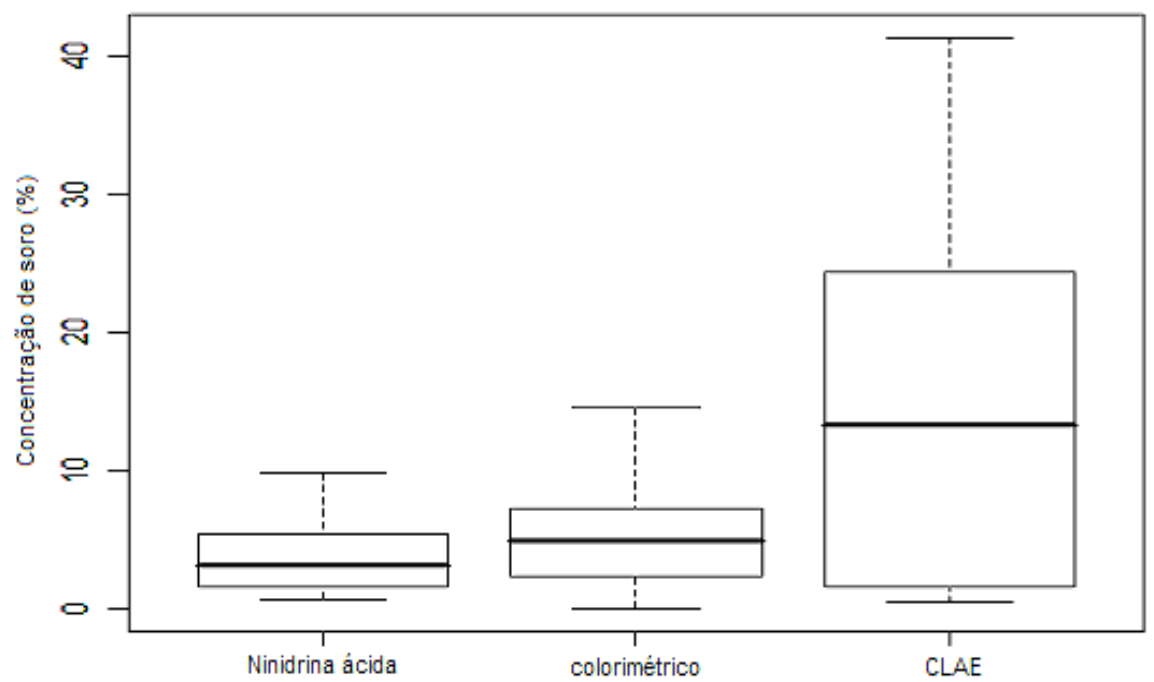

Figura 2. Representação gráfica da comparação entre as metodologias para detecção e quantificação de soro no leite, por meio das médias, valores mínimos e máximos.

Pode-se inferir, com base no desvio padrão, que houve uma variabilidade entre a média amostral e a verdadeira média entre cada metodologia, principalmente, entre a CLAE e as demais técnicas. Diante dos dados obtidos, juntamente com os valores mínimos e máximos para cada método, CLAE (0\% e 41,36\%), colorimétrico $(0 \%$ e $14,51 \%)$ e da ninidrina ácida $(0,20 \mu \mathrm{g} / \mathrm{mL}$ e $9,82 \mu \mathrm{g} / \mathrm{mL}$ ), observa-se que, apesar de a CLAE diferir dos demais métodos, o colorimétrico adaptado e o da ninidrina ácida não apresentaram diferença significativa. Admite-se, portanto, que o método colorimétrico adaptado e o da ninidrina ácida são ferramentas eficientes e de suma importância na triagem de amostras destinadas à análise laboratorial para detecção de soro em leite cru, corroborando Fukuda et al. (1996), que relataram ser o método da ninidrina ácida um teste para "screening" na classificação do leite recebido pelas indústrias de laticínios.

Closs e Souza (2011) detectaram o teor de CMP pelo método cromatográfico e pelos métodos espectrofotométricos na região do visível que utilizam a ninidrina ácida e o reativo Erlich para quantificação do ácido siálico. Os autores detectaram que os métodos espectrofotométricos apresentaram coeficientes de correlação superiores a 0,97 com o método cromatográfico estabelecido pela legislação brasileira vigente.

Com base na quantidade de amostras que apresentaram CMP elevado, Fukuda (2003) relatou que o congelamento das amostras pode afetar os resultados do teor de CMP, tanto pela metodologia CLAE, quanto pela ninidrina ácida. A autora sugere o envio do filtrado de TCA, em vez da amostra congelada.

Em 2004, Fukuda e colaboradores indicaram a técnica da ninidrina ácida para determinação quantitativa do ácido siálico em leite e o método colorimétrico para a detecção e a quantificação do CMP como técnicas substitutas da CLAE pelos seguintes motivos: fácil execução, rapidez e eficiência na detecção rotineira da adição fraudulenta de soro de queijo ao leite fluido. Fukuda et al. (2004) sugerem que a CLAE, metodologia sofisticada de alta sensibilidade, precisão e acurácia, seja utilizada em caso dúbio e em contraprova, por ser um processo oneroso, demorado, trabalhoso e que requer mão de obra qualificada. Somam-se a isso o custo da 
manutenção e o tempo de vida útil das colunas cromatográficas.

Atualmente, existem várias metodologias disponíveis para análise quantitativa do soro, como, por exemplo, a técnica da cromatografia em fase reversa (Thoma et al., 2006), que, segundo os autores, constitui ferramenta eficiente na detecção das principais proteínas do soro e do CMP. Porém, a CLAE por exclusão molecular SEC metodologia utilizada neste trabalho, vem sendo consagrada pela sua eficiência e sensibilidade.
De acordo com a IN69 de 13 de dezembro de 2006, que instituiu critério de avaliação da qualidade do leite in natura, os leites que apresentarem índices de CMP de até $30 \mathrm{mg} / \mathrm{L}$ devem ser destinados ao abastecimento direto, os que estiverem entre $30 \mathrm{mg} / \mathrm{L}$ e $75 \mathrm{mg} / \mathrm{L}$, enviados à produção de derivados lácteos, e acima de $75 \mathrm{mg} / \mathrm{L}$, encaminhados para alimentação animal e/ou indústria química (Brasil, 2006). Assim, observa-se a classificação das amostras, quanto à quantidade de CMP, avaliadas pelas técnicas CLAE, de ninidrina e colorimétrico adaptado (Tab. 2).

Tabela 2. Percentual de amostras de leite cru refrigerado quanto ao teor de CMP

\begin{tabular}{cccc}
\hline Quantidade de CMP $(\mathrm{mg} / \mathrm{L})$ & CLAE & Ninidrina ácida & $\begin{array}{c}\text { Colorimétrico } \\
\text { adaptado }\end{array}$ \\
\hline$<30$ & 31,25 & 50,00 & 37,50 \\
$\geq 30$ a $<75$ & 6,25 & 37,50 & 37,50 \\
$\geq 75$ & 62,50 & 12,50 & 25,00 \\
\hline
\end{tabular}

Pesquisadores têm citado a ocorrência de soro de queijo em amostras de leite e derivados lácteos. Oancea (2009), ao utilizar o Stick cGMP para detecção de soro de queijo em amostras comerciais de leite, observou a presença de altos teores de CMP em 70\% das amostras investigadas. Almeida et al. (2006) avaliaram 40 amostras de leite cru coletadas no estado de Goiás, mantidas armazenadas por 24 e 48 horas, e verificaram que $100 \%$ das amostras analisadas quanto à presença de CMP apresentavam resultados negativos. Closs e Souza (2011) detectaram aumento do teor de CMP ao longo do período de armazenamento. Portanto, esse fator deve ser considerado para separar um leite fraudado de um com atividade proteolítica.

\section{CONCLUSÃO}

De acordo com os resultados encontrados, concluiu-se que a CLAE é a metodologia de maior sensibilidade na determinação do soro de queijo em leite, e os métodos de ninidrina ácida e colorimétrico adaptado são os mais empregados na triagem tendo em vista a detecção e a quantificação de soro de queijo em leite.

\section{REFERÊNCIAS}

ALMEIDA, T.L.; COELHO, K.O.; NICOLAU, E.S. et al. Determinação de caseinomacropeptídeo em amostras de leite cru refrigerado submetido a diferente tempo de armazenamento. In: CONGRESSO BRASILEIRO DE QUALIDADE DO LEITE, 2., 2006, Goiânia. Anais... Goiânia: CBQL, 2006. Disponível http://www.terraviva.com.br/IICBQL/p002.pdf. Acessado em: 02 nov. 2016

ANDRADE, E.H.P.; SOUZA, M.R.; FONSECA, L.M. et al. Detection of cheese whey and caseinomacropeptide in fermented milk beverages using high performance liquid chromatography. Arq. Bras. Med. Vet. Zootec., v.66, p.959-964, 2014.

BRASIL. Ministério da Agricultura e Reforma Agrária. Portaria nº 124 de 23 set. 1991, aprova métodos analíticos qualitativo e quantitativo de detecção de soro em leite. Diário Oficial da União, 20 nov. 1991, p.26245-26246.

BRASIL. Ministério da Agricultura, Pecuária e Abastecimento. Instrução Normativa $n^{\circ}$ 69, de 13 de dezembro de 2006. Institui Critério de avaliação da qualidade do leite in natura, concentrado e em pó, reconstituídos, base com nenhum método analítico oficial físico-químico denominado "Índice CMP", de que trata uma instrução normativa $\mathrm{n}^{\circ} 68$, de 12 de dezembro de 2006. Diário Oficial da União, Brasília, 15 de dezembro de 2006, Seção I, p.67. 
BREMER, M.G.E.G.; KEMMERS-VONCKEN, A.E.M.; BOERS, E.A.M. et al. Enzyme-linked immunosorbent assay for the detection of bovine rennet whey powder in milk powder and buttermilk powder. Int. Dairy J., v.18, p.294-302, 2008.

CLOSS, E.; SOUZA, C.F.V. Avaliação do teor de caseinomacropeptídeo (CMP) nos leites cru e UAT ao longo do tempo de armazenamento. Rev. Bras. Pesqui. Aliment., v.2, p.111-119, 2011.

DIAS, S.S.; LOBATO, V.; VERRUMA-BERNARDI, M.R. Metodologias para identificar adulteração em queijos produzidos com leite de diferentes espécies de animais. Rev. Inst. Adolfo Lutz, v.68, p.327-333, 2009.

FUKUDA, S.P. Estudo da correlação entre o método da ninidrina ácida e a cromatografia líquida de alta eficiência para a dosagem de glicomacropeptídeo e caseinomacropeptídeo em leite. 2003. 149f. Tese (Doutorado em Tecnologia de Alimentos) - Faculdade de Engenharia de Alimentos, Universidade Estadual de Campinas, Campinas, SP.

FUKUDA, S.P.; ROIG, S.M.; PRATA, L.F. Aplicação do método da ninidrina ácida como teste de "screening" de plataforma para a detecção da adição de soro ao leite. Rev. Cienc. Tecnol. Aliment., v.16, p.52-56, 1996

FUKUDA, S.P.; ROIG, S.M.; PRATA, L.F. Correlation between acidic ninhydrin and HPLC methods to evaluate fraudulent addition of whey in milk. EDP Sci., v.84, p.501-512, 2004.

HERNÁNDEZ, C.M., MUÑOZ. M., DAURY. C. et al. Immunochromatographic lateral-flow test strip for the rapid detection of added bovine rennet whey in milk and milk powder. Int. Dairy J., v.19, p.205-208, 2009.

MAREZE, J.; MARIOTO, L.R.M. Detecção de adulterações do leite pasteurizado por meio de provas oficiais. Semina, v.36, p.283-290, 2015.

MARQUES, F.M.; SÁ, J.F.O.; SANTOS, M.C. et al. Caracterização de leite em pó, soro de leite em pó e suas misturas por eletroforese em gel de poliacrilamida. Rev. Inst. Adolfo Lutz, v.70, p.473-479, 2011.
MIRALLES, B.; RAMOS, M.; AMIGO, L. Influence of proteolysis of milk on the whey protein to total protein ratio as determined by capillary electrophoresis. J. Dairy Sci., v.86, p.2813-2817, 2003.

NONI, I.D.; RESMINI, P.; GONZAGA, N. et al. V. Identification of re nnet-whey solids in "traditional butter" by means of HPLC/ESI-MS of nonglycosylated caseinomacropeptide A. Food Chem., v.93, p.65-72, 2005

OANCEA, S. Identification of glycomacropeptide as indicator of milk and dairy drinks adulteration with whey by immunochromatographic assay. Rom. Biotechnol. Lett., v.14, p.4.146-4.151, 2009.

OLIVEIRA, G.R.; GONÇALVES, J.R.; OLIVEIRA, W.M.B. Determinação de fraude de leite com soro (ácido siálico) - método colorimétrico adaptado. Viçosa: Centro de Pesquisa em Alimentos da Escola de Veterinária da UFG. 1998.

PRATA, L.F.; PRATA, C.B. Determinação de GMP e CMP* no leite por métodos espectrofotométrico (ANSM) e cromatográfico (HPLC) - parâmetros metodológicos. Arch. Vet. Sci., v.17, p.29-39, 2012.

SHARMA, N.R.; RAIPUT, Y.S.; MANN, B. Chemical and functional properties of glycomacropeptide (GMP) and its role in the detection of cheese whey adulteration in milk: a review. Dairy Sci. Technol., v.93, p.21-43, 2013.

THOMA, C.; KRAUSE, I.; KULOZIK, U. Precipitation behavior of caseinomacropeptides and their simultaneous determination with whey by RPHPLC. Int. Dairy J., v.4, p.285-293, 2006.

VELOSO, A.C.A.; TEIXEIRA, N.; FERREIRA, I.M.P.V.L.O.; FERREIRA, M.A. Detecção de adulterações em produtos alimentares contendo leite e/ou proteínas lácteas. Quím. Nova, v.25, n.4, p.609-615, 2002. 